\title{
Considerations on material thickness influence on the AWJ processing quality of an aluminium alloy
}

\author{
Eugen Herghelegiu ${ }^{1, *}$, Maria Crina Radu $^{1}$, Carol Schnakovszky ${ }^{1}$, and Catalin Nicolae Tampu ${ }^{1}$ \\ ${ }^{1}$ Vasile Alecsandri University of Bacau, Calea Marasesti 157, 600115, Bacau, Romania
}

\begin{abstract}
The aim of the current paper is to determine the influence of material thickness on the quality aspects of AWJ processing of the AL6061T651 alloy. The analysis is performed under different working conditions. The parameters taken into account to quantify the quality of processing are those defined in the ISO/WD/TC $44 \mathrm{~N} 1770$ standard: width of the processed surface at the jet inlet ( $\mathrm{Li})$, width of the processed surface at the jet outlet (Lo), deviation from perpendicularity (u), inclination angle $(\alpha)$ and roughness $(\mathrm{Ra})$. The obtained results emphasise a significant influence of material thickness on both, the surface quality and process productivity.
\end{abstract}

\section{Introduction}

Industrial development led to the discovery of new materials that cannot be processed by conventional methods, so that it was necessary to develop new technologies that allow the materials processing. The newest technologies are the unconventional technologies, which use the power of electricity, water, air, chemicals etc. Among them, waterjet processing is of great interest for different industrial fields since it can be used for processing of both, soft or hard metallic and non-metallic materials (the processing of hard materials requires the addition into the water jet of an abrasive material and the process is named abrasive waterjet processing - AWJ) [1,2]. Besides, this technology has many other advantages, such as: it is environmentally friendly, it does not degrade thermally the processed surface, in most of cases no additional processing is required, it allows obtaining various complex shapes (using 5-axis machines) since it is CNC controlled. However, it does has some disadvantages as the high cost of equipment, the high cost of maintenance and spare parts, the need for skilled workers, the impossibility to process pieces in package [3,4 ].

The parameters used to describe the quality of a cut performed by abrasive waterjet technology are defined by the ISO/WD/TC $44 \mathrm{~N} 1770$ standard and are as follows (fig. 1): width of the processes surface at the je inlet $(\mathrm{Li})$, width of the processed surface at the jet outlet (Lo), deviation from perpendicularity $(\mathrm{u})$, inclination angle of the processed surface $(\alpha)$ and surface roughness (Ra) [6].

\footnotetext{
* Corresponding author: eugen.herghelegiu@ub.ro
} 


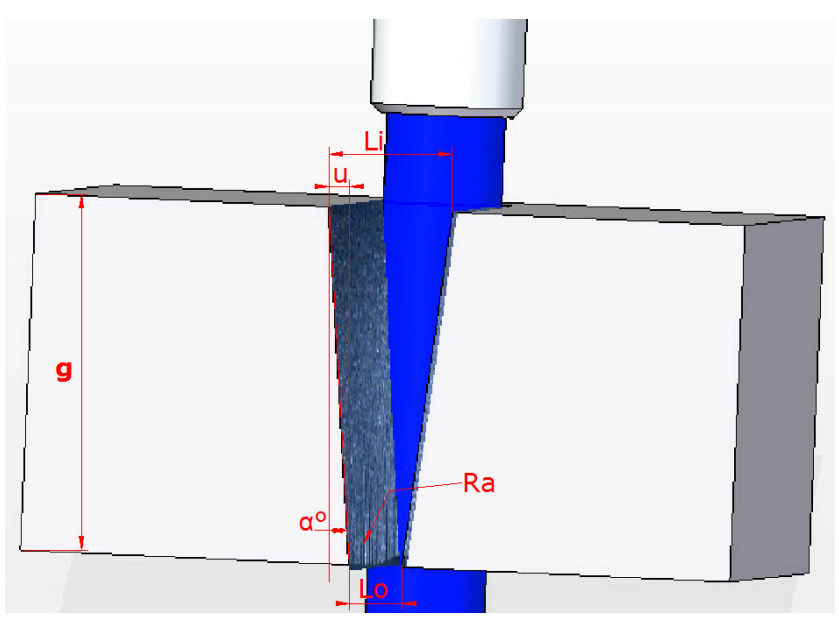

Fig. 1. Parameters used to quantify the quality of cut processed by AWJ $[5,6]$.

The aim of the current paper is to investigate the influence of the material thickness on the quality of cuts performed by abrasive water jet technology.

\section{Experimental methodology}

The experimental study was performed on the Al 6061 T651 alloy, with three thicknesses of samples: $1 \mathrm{~mm}, 6.5 \mathrm{~mm}$ and $10 \mathrm{~mm}$. This material is widely used in the aeronautical industry for various components of the aircraft, where the parts must be of high quality, without any heat affected zone of the processed surfaces. The experimental tests consisted in performing simple linear cuts through the material thickness, which allow to measure the analysed quality parameters (presented in fig. 1). Measurements for roughness were taken in the middle of the thickness of cut surface (for the thickness of $1 \mathrm{~mm}$ ). For 6.5 and $10 \mathrm{~mm}$, the measuring location was at $1 \mathrm{~mm}$ from the bottom surface (fig. 2).

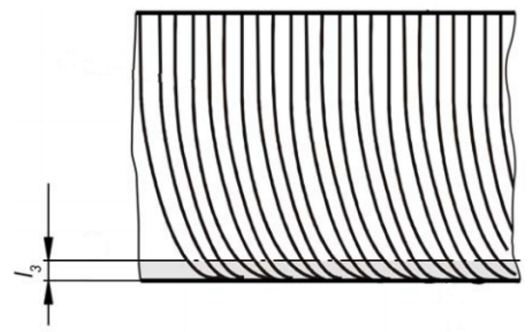

Fig. 2. Measurement of roughness $\left(l_{3}=1 \mathrm{~mm}\right.$ for the thickness of cut surface equal to 6.5 and $\left.10 \mathrm{~mm}\right)$.

The chemical composition of the material and its mechanical characteristics are presented in table 1 and table 2.

The experimental tests were performed on a Hydro-Jet Eco 0615 machine (fig. 3), equipped with a piston pump, capable of providing a maximum pressure of $150 \mathrm{MPa}$. Two process parameters were varied:

- feed rate (Vf), for which two values were used: $50 \mathrm{~mm} / \mathrm{min}$ and $100 \mathrm{~mm} / \mathrm{min}$;

- distance between the cutting head and sample (h), with also two values: $1 \mathrm{~mm}$ and $3 \mathrm{~mm}$.

The parameters that were kept constant during the experiments are presented in table 3. 
Table 1. Chemical composition of the Al $6061 \mathrm{~T} 651$ alloy.

\begin{tabular}{|c|c|c|c|c|c|c|c|c|c|c|c|}
\hline \multirow{2}{*}{ Grade } & $\mathrm{Si}$ & $\mathrm{Fe}$ & $\mathrm{Cu}$ & $\mathrm{Mn}$ & $\mathrm{Mg}$ & $\mathrm{Cr}$ & $\mathrm{Zn}$ & $\mathrm{Ti}$ & Other elements & $\mathrm{Al}$ \\
\cline { 2 - 11 } & $\%$ & $\%$ & $\%$ & $\%$ & $\%$ & $\%$ & $\%$ & $\%$ & each & total & $\%$ \\
\hline $\begin{array}{c}\mathrm{Al} \\
6061 \\
\mathrm{~T} 651\end{array}$ & 0.64 & 0.2 & 0.18 & 0.07 & 1 & 0.06 & 0.12 & 0.08 & 0.05 & 0.15 & rest \\
\hline
\end{tabular}

Table 2. Mechanical characteristics of the Al 6061 T651 alloy.

\begin{tabular}{|c|c|c|c|c|c|c|}
\hline \multirow{3}{*}{ Grade } & \multicolumn{2}{|c|}{$\begin{array}{c}\text { Ultimate tensile strength, } \\
\text { Rm }\end{array}$} & \multicolumn{2}{c|}{ Elongation, A } & \multicolumn{2}{c|}{$\begin{array}{c}\text { Yield Strength, } \\
\text { Rpo,2 }\end{array}$} \\
\cline { 2 - 7 } & \multicolumn{2}{|c|}{$[\mathrm{N} / \mathrm{mm} 2]$} & \multicolumn{2}{c|}{$[\%]$} & \multicolumn{2}{c|}{$[\mathrm{N} / \mathrm{mm} 2]$} \\
\cline { 2 - 7 } & $\min$ & $\max$ & $\min$ & $\max$ & $\min$ & $\max$ \\
\hline $\begin{array}{c}\text { Al 6061 } \\
\text { T651 }\end{array}$ & 311.6 & 315.7 & 14 & 15 & 294.4 & 295.7 \\
\hline
\end{tabular}

Table 3. Constant process parameters.

\begin{tabular}{|l|c|c|}
\hline \multicolumn{1}{|c|}{ Parameter } & Unit & Value \\
\hline Water pressure, $P$ & {$[\mathrm{MPa}]$} & 150 \\
\hline Quantity of abrasive material, $\mathrm{Q}$ & {$[\mathrm{g} / \mathrm{min}]$} & 300 \\
\hline Orifice diameter, $\mathrm{d}_{\mathrm{o}}$ & {$[\mathrm{mm}]$} & 0.35 \\
\hline Length of focusing tube, $\mathrm{L}_{\mathrm{f}}$ & {$[\mathrm{mm}]$} & 76 \\
\hline Diameter of focusing tube, $\mathrm{D}_{\mathrm{f}}$ & {$[\mathrm{mm}]$} & 1.02 \\
\hline Garnet Mesh & {$[\#]$} & 80 \\
\hline
\end{tabular}

The quality parameters of cuts were measured by using a Leica MZ75 microscope with PC interface and a Mitutoyo SJ 201 digital roughness device.

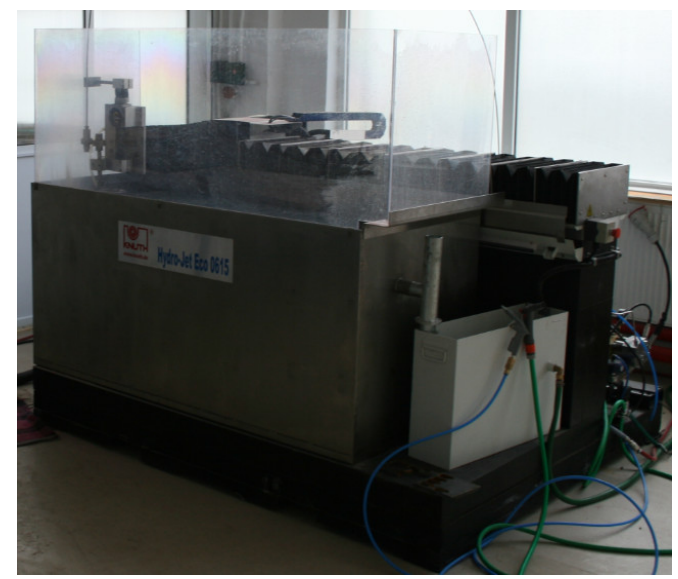

Fig. 3. Water jet cutting machine Hydro-jet Eco 0615.

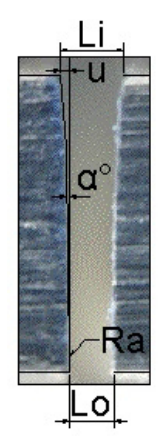

Fig. 4. Sample after cutting. 


\section{Results and discussion}

The results of measurements of the parameters that quantify the quality of cuts are comparatively presented in the graphs from figures 5, 6 and 7 .

By analyzing the graphs from figure $5 \mathrm{a}, \mathrm{b}$ one can observe that as the material thickness increases, the width of the processed surface at the jet inlet (Li) decreases, with the same trend regardless the feed rate of the cutting head. However, the higher value of the feed rate led to narrower cuts; the explanation is related to the number of abrasive particle that get in contact with the sample material, which is becoming smaller as the feed rate increases. This effect is more visible in case of processing the sample of $1 \mathrm{~mm}$ thickness, with the distance between sample and the cutting head of $3 \mathrm{~mm}$.

The graphs from figure $5 \mathrm{c}, \mathrm{d}$ show the variation of the width of the processed surface at the jet outlet (Lo) with the thickness of sample: the Lo parameter decreases as the sample is getting thicker. This effect is valid for both values of the feed rates as well as for both values of the distance between the cutting head and sample.

Distance between the cutting head and working sample, $h=1 \mathrm{~mm}$

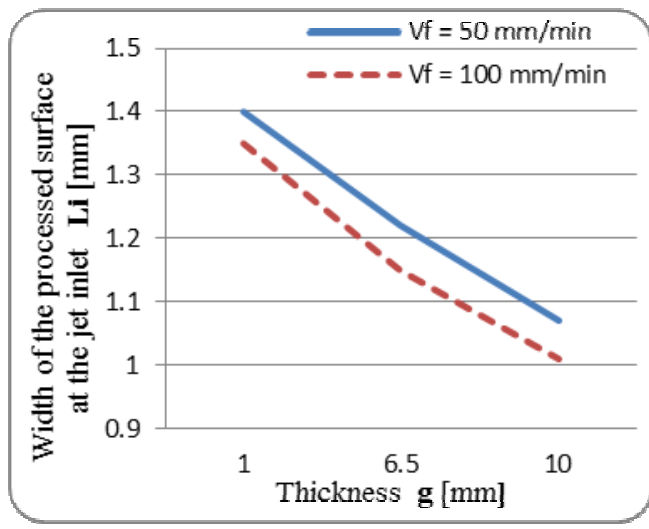

a.

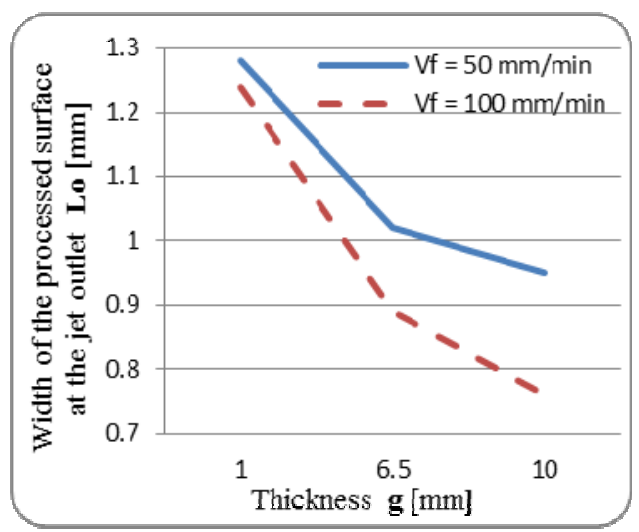

c.
Distance between the cutting head and working sample, $h=\mathbf{3} \mathrm{mm}$
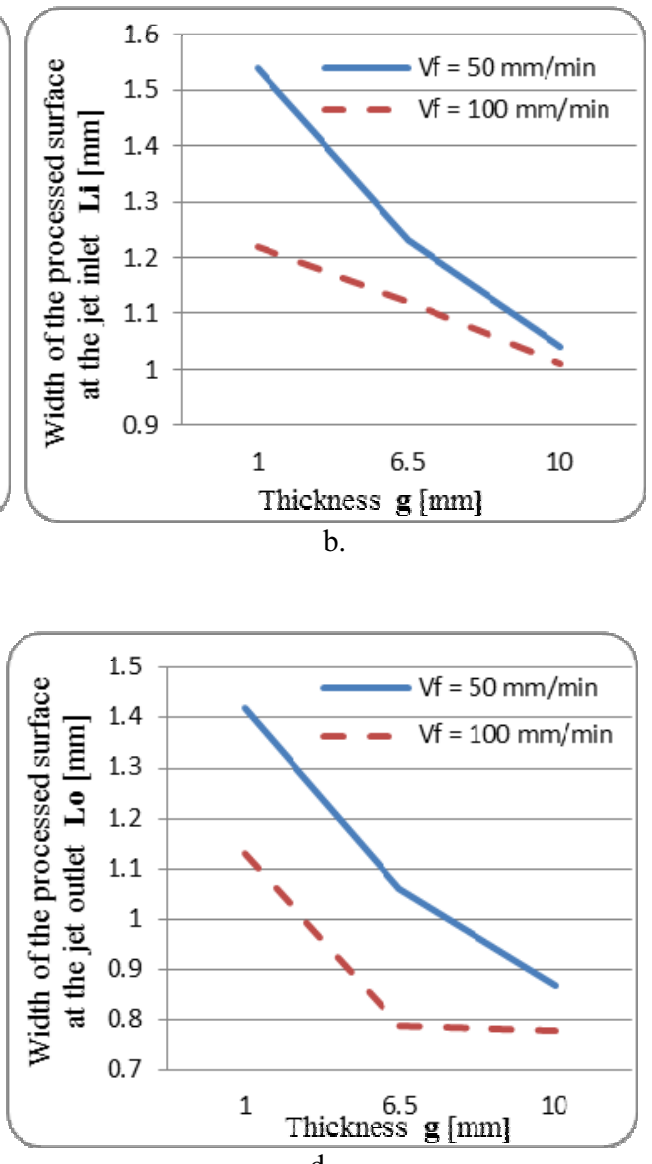

d.

Fig. 5. Influence of the feed rate and distance between the cutting head and material on the Li and Lo. 


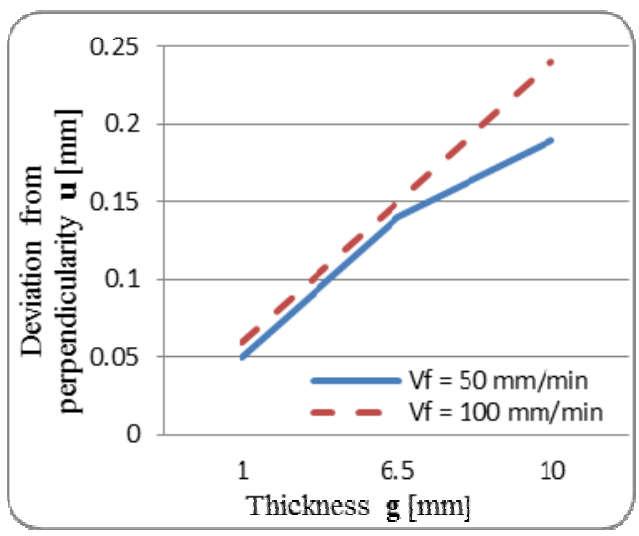

a.

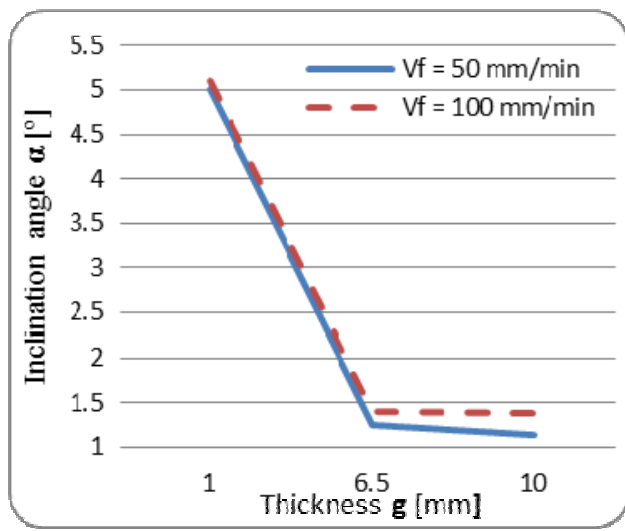

c.

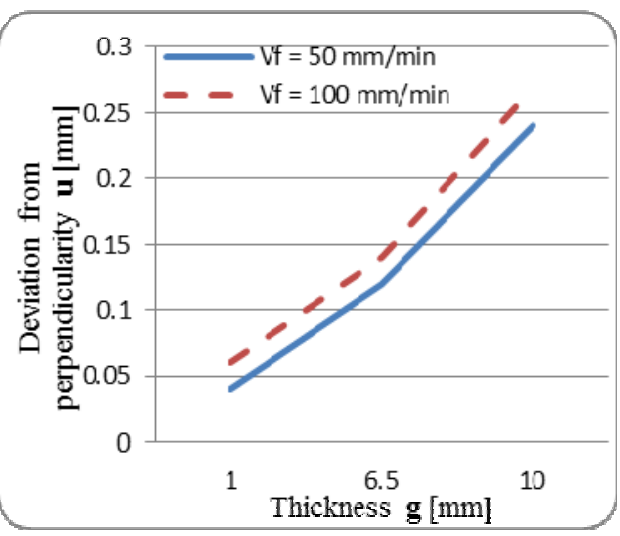

b.

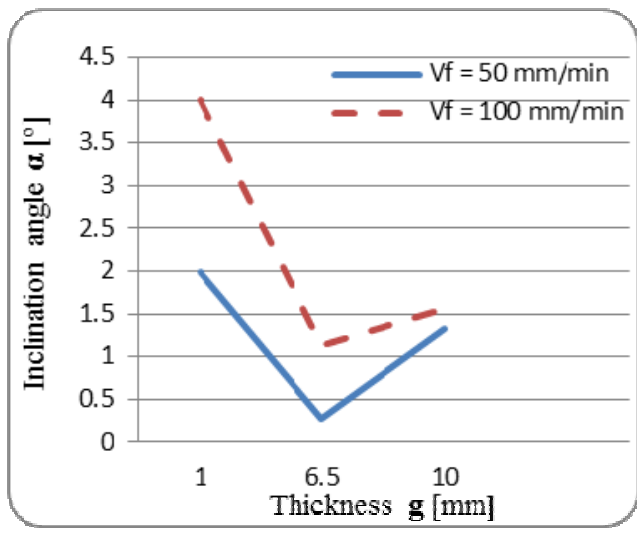

d.

Fig. 6. Influence of the feed rate and distance between the cutting head and material on the $u$ and $\alpha$.

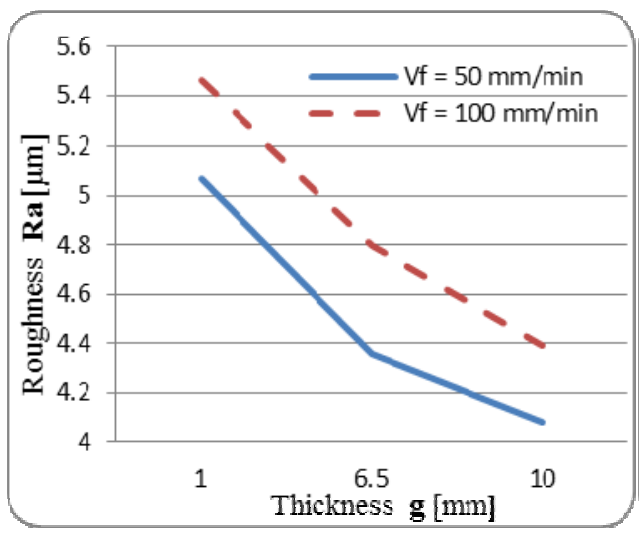

a.

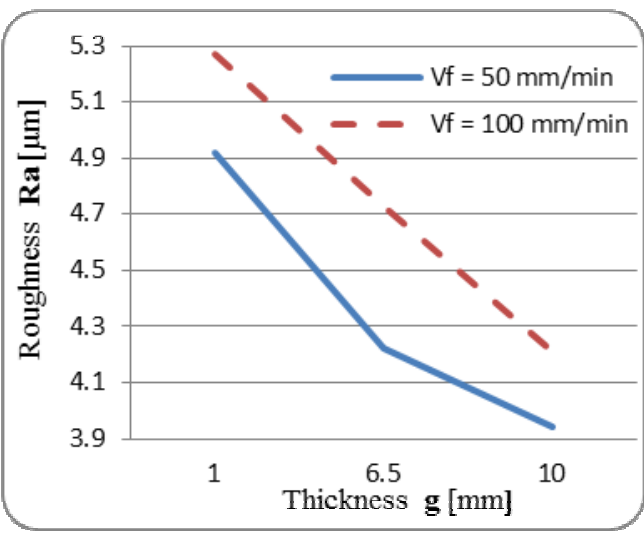

b.

Fig. 7. Influence of the feed rate and distance between the cutting head and material on the roughness. 
The deviation from perpendicularity (u) increases as the sample thickness increases (fig. $6 \mathrm{a}, \mathrm{b})$. Smaller values of deviations were obtained in case of processing with a lower feed rate. The influence of the distance between the cutting head and sample is insignificant.

The inclination angle $(\alpha)$ decreases as the sample is thicker. This curious variation, (contrary to fig. 1) is due to the fact that the inclination is not the same on the cut thickness (fig. 4). The increase of the feed rate leads to an increase of the inclination angle while the effect is opposite when the distance between the cutting head and sample is getting bigger (fig. $6 \mathrm{c}, \mathrm{d}$ ).

The roughness of the processed surface $(\mathrm{Ra})$ is getting smaller as the thickness of sample increases. The increase of feed rate leads to an increase of roughness regardless the sample thickness, while a bigger distance between the cutting head and sample cause a slight reduction of material roughness (fig. $7 \mathrm{a}, \mathrm{b}$ ).

\section{Conclusions}

The obtained results emphasize a significant influence of the material thickness on the quality of cuts performed by abrasive waterjet technology. All the analysed parameters are getting smaller, as the sample thickness increases, excepting the deviation from perpendicularity. This may be an important gain if we take into account the difficulty or even the impossibility of cutting hard materials with the conventional technologies. The effect is amplified (in terms of width of the processed surface at the jet inlet/outlet) when higher feed rates are used; on the contrary, the surface roughness is getting coarser as the cutting head is moving faster. The increase of feed rate means a higher productivity, leading in the meantime to good values of some parameters that quantify the quality of cuts ( $\mathrm{Li}, \mathrm{Lo})$, even for thicker material. However, there are other quality parameters $(\mathrm{u}, \alpha$ and $\mathrm{Ra}$ ) whose variation with the feed rate is opposite. Therefore, the feed rate should be chosen so that to obtain an optimum between the quality of cut and process productivity. Further research will be performed in view of this. The distance between the cutting head and sample slightly affects the quality of cuts, its influence being more accentuate in case of processing with higher feed rates.

This paper was performed through the Partnerships program in PN II priority areas, developed with MEN-UEFISCDI (Romanian National Authority for Scientific Research) support, project no. 294/2014.

\section{References}

1. E. Herghelegiu, C. Radu, C. Schnakovszky, V. Zichil, Appl. Mech. Mater. 809-810, 207 (2015)

2. P. Janković, M. Radovanović, Annals of the Oradea University. Fascicle of Management and Technological Engineering. 7, 1528 (2008)

3. M. Chithirai Pon Selvan, N. Mohana Sundara Raju, Int. J. Eng. Sci. Technol. 7, 254 (2011)

4. C. Schnakovszky, E. Herghelegiu, M. C. Radu, I. Cristea, Adv. Mat. Res. 837, 196 (2014)

5. E. Herghelegiu, M. C. Radu, C. Schnakovszky, I. Cristea, Appl. Mech. Mater. 371, 240 (2013)

6. $* * *$ ISO/ WD/ TC 44 N $1770-2010$. 